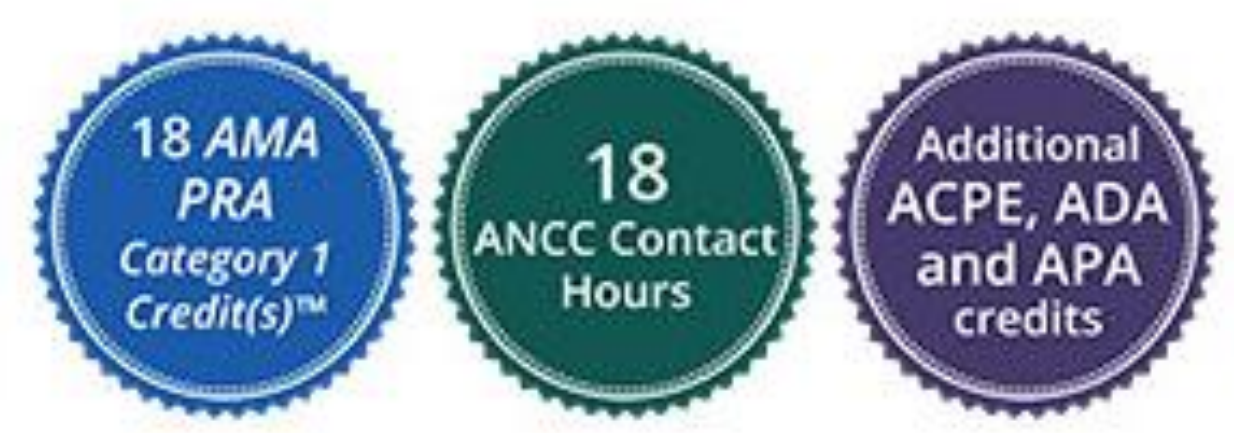

\title{
Quality of dying and death during the last hospitalization of advanced cancer patients: A retrospective cohort study
}

\author{
Panpan Cuii ${ }^{1}$, Shiqi Dong ${ }^{1}$, Xinyi Gao ${ }^{1}$, Yiyang Chen ${ }^{1}$, Han Tang ${ }^{1}$, Changying Chen ${ }^{1} 2^{\star}$ \\ 1 Nursing College of Zhengzhou University, Henan, China \\ 2 The First Affiliated Hospital of Zhengzhou University, Henan, China \\ * Corresponding author
}

\section{Introduction}

Patients with advanced cancer are often cared for and die in hospitals in China. However, there is limited evidence about how end-of-life care is delivered during the last hospitalization before death in mainland China.

\section{Objectives}

The aims of this study were to:

1. Describe the symptoms terminal cancer patients experienced;

2. Describe the supportive measures advanced cancer patients received during the last hospitalization.

\section{Methods}

Method. A retrospective cohort study.

Setting. Three tertiary hospitals of Henan province, China.

Sample. Cancer decedents (aged $\geq 18$ years) between January 2016 to December 2017 during the last hospitalization before death were recorded in the electronic medical record. Those who died from non-cancer related causes were excluded.

Measurement. A data extraction form was developed by the research team. It was composed of:

(1) Patients' characteristics;

(2) Cancer-related symptoms;

(3) Supportive measures

\section{Results}

- 427 cancer decedents were included in the study. Characteristics of the patients are listed in Table 1.

- Pain, loss of appetite and fatigue ranked the top three most common symptoms (Figure 1).

- Morphine was the most frequent analgesic. No measures targeting fatigue were documented. Psychological support was recorded in $39.8 \%$ of patients, just referring to the terms of psychological guidance or mental nursing without any other detailed information. No spiritual information was found in all of the charts (Table 2).

$\begin{array}{llllllll}50 & 100 & 150 & 200 & 250 & 300 & 350 & 400\end{array}$

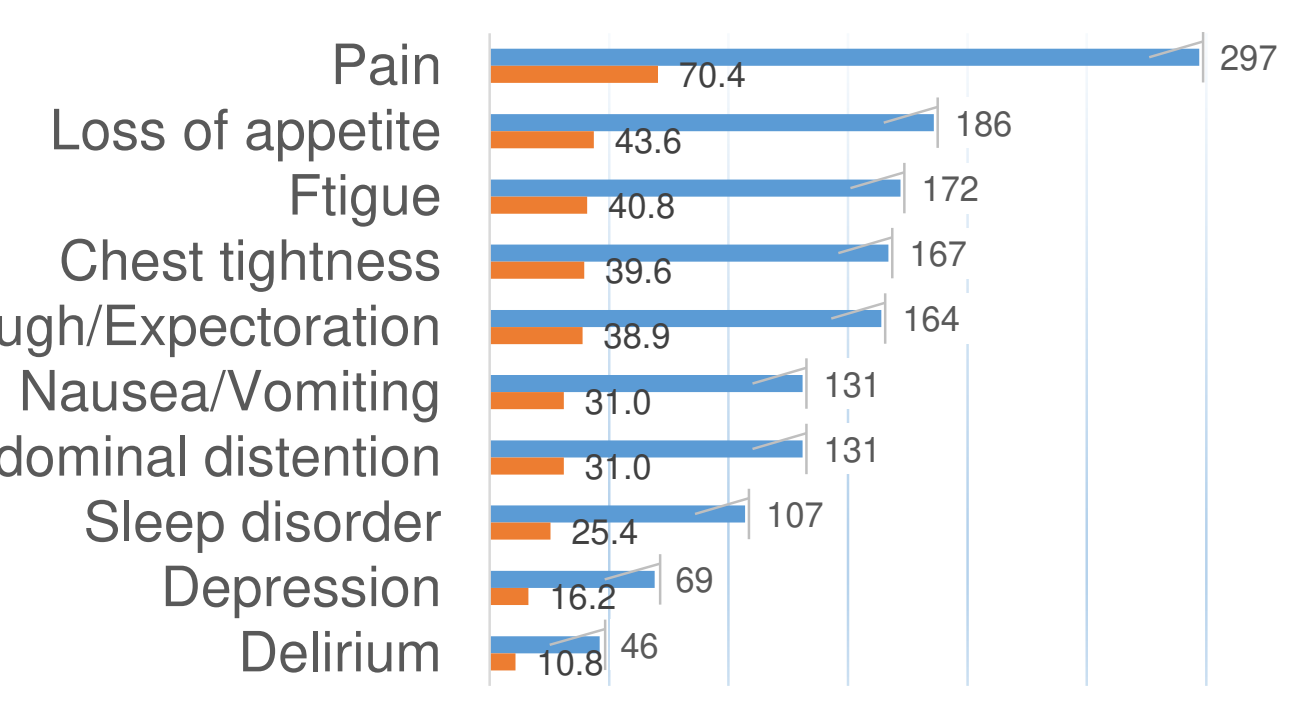

- Frequency $\quad$ Percentage (\%)

Figure 1 Symptom frequency of the study sample $(n=427)$
Table 1 Characteristics of the study sample $(n=427)$

\begin{tabular}{lll}
\hline Characteristics & Cases, $\mathrm{n}$ & Percentage (\%) \\
\hline Age (mean, SD) & $66.2(13.4)$ & \\
$\quad$ > 65 y of age & 229 & 53.6 \\
$\quad$ S65 y of age & 198 & 46.4 \\
Sex & & \\
$\quad$ Male & 268 & 62.8 \\
$\quad$ Female & 159 & 37.2 \\
Marital status & & \\
$\quad$ Married & 385 & 90.2 \\
$\quad$ Unmarried & 42 & 9.8 \\
Place of residence & & \\
Urban & 406 & 95.1 \\
$\quad$ Rural & 21 & 4.9 \\
Primary cancer & & \\
Lung & 138 & 32.3 \\
Liver & 48 & 11.2 \\
Gastric & 34 & 8.0 \\
Colorectal & 31 & 7.3 \\
Pancreatic & 26 & 6.1 \\
Others & 133 & 35.1 \\
\hline
\end{tabular}

Table 2 Supportive measures received during the last hospitalization among advanced cancer patients $(n=427)$

\begin{tabular}{lll}
\hline Supportive measures & Cases, $\mathrm{n}$ & Percentage (\%) \\
\hline Analgesics & & \\
$\quad$ No & 123 & 28.8 \\
$\quad$ Opioids & 251 & 58.8 \\
$\quad$ Non-opioids or weak opioids & 53 & 12.4 \\
Psychological support & & \\
$\quad$ No & 257 & 60.2 \\
$\quad$ Psychological guidance & 73 & 17.1 \\
$\quad$ Psychological nursing & 66 & 15.4 \\
$\quad$ Others & 31 & 7.3 \\
Nutritional support & & \\
$\quad$ By mouth & 116 & 27.2 \\
$\quad$ Enteral nutrition & 56 & 13.1 \\
$\quad$ Parenteral nutrition & 76 & 17.8 \\
$\quad$ By mouth \& Parenteral nutrition & 72 & 16.9 \\
$\quad$ Enteral \& Parenteral nutrition & 84 & 19.6 \\
$\quad$ Others & 23 & 5.4 \\
\hline
\end{tabular}

\section{Conclusions}

Quality of end-of-life care for cancer patients during the last hospitalization was not optimistic. More attention need to be paid to symptom control, such as pain and fatigue. Psychological or existential/spiritual needs need to be well documented and addressed in the future.
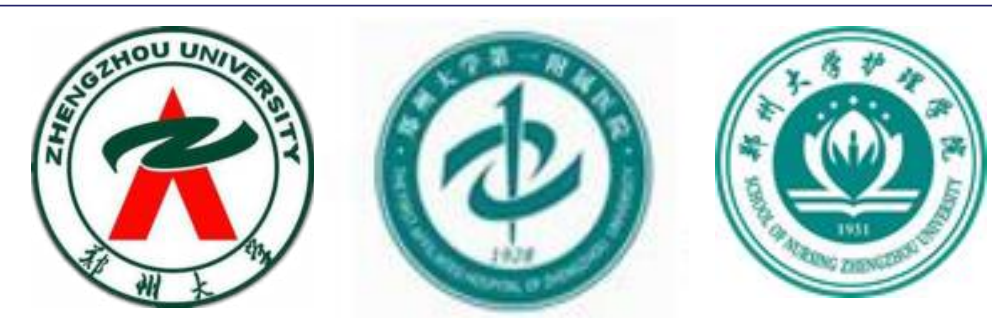